\title{
Implementation of Business Intelligence for Coal Production and Reserves Division
}

\author{
Anggi Tri Rizki RAMADHANI ${ }^{1}$, Ken Ditha TANIA $^{2 *}$ \\ Ianggitririzki2@gmail.com, Information System Department, Faculty of Computer Science, \\ Sriwijaya University, Palembang, Indonesia \\ ${ }^{2}$ kenya.tania@gmail.com, Information System Department, Faculty of Computer Science, \\ Sriwijaya University, Palembang, Indonesia \\ *Corresponding author: kenya.tania@gmail.com
}

\begin{abstract}
In this era of globalization business competitions among the company increased. Companies need knowledge of information technology to support companies to be able to predict the future and help the whole system to improve services. Business Intelligence as a system that can help management by providing predictions, patterns, and assisting in decision making. In designing and implementing Business Intelligence for coal production and reserves division using Business Intelligence Roadmap method. Business Intelligence Roadmap is one of the methods of Business Intelligence that can be used because it is adaptive and detail which consists of 6 phases and 18 stages. By implementing Business Intelligence within the coal company environment is expected to support the strategic decisions related to the plans and predictions of coal production that need to be taken, so the management of coal production operations can run well, and it can produce business information in a short time. Data and information generated also become more accessible and easier to understand with focused on making reports in the form of visualizations such as diagrams and charts.
\end{abstract}

Keywords: Business Intelligence, Business Intelligence Roadmap, coal company, OLAP, the implementation of intelligence business

\section{Introduction}

Business Intelligence is a set of theories, stages of integrating data, processes, architecture, and information technology that transforms separate operational data into centralized to gain meaningful and useful information for business purposes [1]. Business Intelligence provides a view of the past, present, and predictions about business operations. The general function of BI technology is for reporting, OLAP, data mining, business performance management, predictive and prescriptive. Its basic components include data warehouse, data mining, OLAP, reporting, spreadsheets, and others [2]. Business Intelligence solutions are currently used mainly by large and medium-sized companies [3], one of them is a coal company. Implementation of Business Intelligence within the coal company environment can support the decisions that must be taken, so that the management of operation coal production can run well in accordance with the Work Plan and Budget (RKAP) that was set at the beginning of the year. Even Business Intelligence can also provide support for strategic decisions related to plans and predictions of the amount of coal production in the following year based on previous years.
PT. Bukit Asam, Tbk has a main focus in coal production to support world energy sources in order to support various energy needs in various regions, factories, or companies. So that in coal production operations each year it takes a careful calculation taking into account the reserves that are still in the warehouse as well as various obstacles that may occur so that no losses occur in the future and in accordance with the RKAP that has been made.

The system that runs on PTBA has used information technology to assist operational activities. The system that supports coal production activities is already available at PTBA, but the integration between the two systems has not yet occurred, which causes frequent discrepancies between the amount of production in the RKAP and the amount of production that occurs in the field. This discrepancy can occur because PTBA often does not see and consider several factors in the field. This can result in losses for the company because it cannot meet the needs of coal operating production, which in turn causes unmet consumer needs.

With the implementation of Business Intelligence to this system, this problem can be minimized and allow the prediction of the amount of coal production for the 
coming year based on historical data from the previous year. Based on the data obtained will be carried out cleaning and data collection in the warehouse. The data contained in the data warehouse will be carried out a data mining process that uses classification methods using Naïve Bayes. Naïve Bayes assumes an underlying probabilistic model and allows to capture uncertainties about the model in a principled way by determining the probability of an outcome [4]. The data will calculate coal production data based on the amount of coal production to the amount of production, and can estimate the probability of coal production for the next year based on predictions from influencing factors. Furthermore, an analysis will be conducted to produce information that can be used by PT. Bukit Asam, Tbk to facilitate the operation of coal production data operations and support the performance of coal production in the field, as well as improve the process of making interesting reports in the form of charts and diagrams so that they can be used and used as a guide in making business decisions for management users.

Business Intelligence as a form of implementation that is able to answer existing needs, especially in handling the coal production process in the company. Business Intelligence has been widely used by companies in managing data and information to support decision making. In addition, the coal production operation process which is quite long will be more effective and efficient if the application of website-based Business Intelligence technology is focused on making reports in the form of visualizations such as diagrams and charts. From these results it can be taken into consideration for PT. Bukit Asam, Tbk, in increasing the amount of coal production so it is expected to be in accordance with the Work Plan and Budget (RKAP) that has been set at the beginning of the year.

\section{RELATED WORKS}

\section{Business Intelligence}

Business Intelligence is defined as systems that collect, transform, and present structured data from multiple sources reducing the needed time to obtain relevant business information and enable their efficient use in management decision making process, allowing dynamic enterprise data search, retrieval, analysis, and explanation of the needs of managerial decisions [5]. Business Intelligence can also be used as an analysis of the historical data of a product in an organization for the financial needs of the systemic policy/strategy/work program within a certain time which can in the future improve the performance of the product [6].

Business Intelligence generate a number of structured data from where they are obtained, through various methods and analyzes the information that management needs to support business processes [3]. Business Intelligence is defined as a framework that combines database management architecture, business analysis, business performance management, and data visualization to manage company data in coal-fired power plants [7].

So that, Business Intelligence is a concept for collecting, changing, and presenting structured data from various sources to be able to provide information so as to help and improve the quality and efficiency in business decision making for an organization. The concept of BI itself is to transform information into new knowledge and understanding for the organization.

\section{Related Research of Business Intelligence}

Several studies related to Business Intelligence have been carried out in various fields, including in the field of Education [8] BI produced a system to provide decisions about the importance of studying the business curriculum so that students have provisions in the future.

In research [1] within the bank, BI helps provide policy decisions for customers to continue to improve transactions and facilitate bank report management.

Research [3] said Business Intelligence is currently used primarily by large and medium-sized companies, one of which is a coal company. Some research on coal companies has been done, such as on research [7] the implementation of Business Intelligence is applied to monitor Key Performance Indicators (KPI), capture insights about the behavior of the power plant process, and identify factors that influence the efficiency of coal combustion. Also on research [9] Implementation BI is used in business process reengineering whose purpose is to solve the problem of stealing or changing coal during loading, reducing pollution, increasing coal loading efficiency and weighing accuracy thereby reducing production costs.

From that, the implementation of Business Intelligence at PT. Bukit Asam, Tbk can be used as an analysis of coal production data in the past by considering and identifying factors that influence the amount of coal production so that it can solve the problem of often not achieving the target of coal production operations and support decision making in determining strategies / policies / work programs to the next period to improve the performance of PT. Bukit Asam, Tbk.

\section{RESEARCH METHOD}

\section{Method of Collecting Data}

Data Type

There are 2 types of data obtained in this study, namely primary data and secondary data. Primary data is basic data at PT. Bukit Asam, Tbk. collected from the place of the object to be examined. Meanwhile, secondary data is data collected through various sources or various literary studies such as journals, internet media, and thesis material related to the problem to be examined.

Data Source

In conducting this research, the source of data obtained from the leaders and employees of PT. Bukit Asam, Tbk through a database managed by the production and planning operations section of PT. Bukit Asam, Tbk. Data Collection 
There are several methods used in the process of collecting data and information used in this study, namely interview, observation, and literature review.

\section{System Development Method}

In designing and implementing Business Intelligence systems development methods will be used using an approach Business Intelligence Roadmap [6].

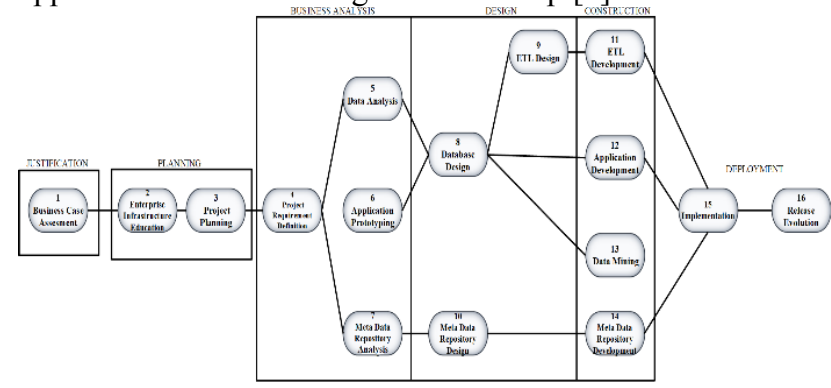

Fig. 1. Business Intelligence Roadmap

Based on the Business Intelligence Roadmap method above there are 6 phases that must be carried out, namely: Justification Phase

In this justification phase, a business case assessment was carried out at PT. Bukit Asam, Tbk, is the first step taken into consideration in the initial steps of developing a BI project.

Planning Phase

After going through justification phase, the next step is planning.

Enterprise Infrastucture Evaluation

The application of the BI concept must be evaluated for infrastructure at PT. Bukit Asam, Tbk as a whole. Previously, the existing infrastructure before implementing the BI concept had infrastructure that had to be developed so that the project for implementing Business Intelligence could be achieved properly.

Project Planning

BI decision making projects are very dynamic so that any changes that occur in the scope, staff, budget, technology, business processes can influence the success of a BI project. Therefore, project planning must be made more detailed and the latest progress must always be monitored and reported.

Business Analysis phase

Focus on conducting a detailed analysis of problems and business opportunities to gain a deep understanding of business needs for product solutions. At this stage there are 4 main steps, namely:

Project Requirement Definition

At this stage it is necessary to review the system development needs such as data requirements, query functions, technical, and non-technical whether it is sufficient to implement BI applications.

Data Analysis

In this Business Intelligence concept, the source of the data obtained from the datahouse is used as a data source (operational database) that has been carried out by the ETL process so that the data obtained is of high quality. After extracting, the data must be cleaned so that the accuracy of the results of the analysis can be guaranteed.
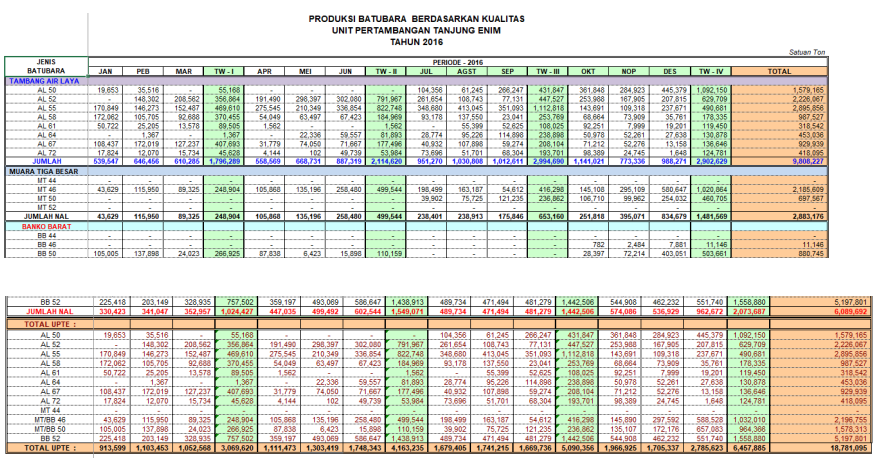

Fig. 2. Example of Coal Production Data

Application Prototyping

The prototype can be used as a means of seeing for potential executives and limitations of BI technology that will be created and can also provide opportunities for them to add or change the needs and expectations of this BI project.

Meta data repository analysis

This stage is done by making a logical meta model that is represented from the metadata object in the form of a Star Schema. The reason for using Star Schema is because the definition of the metadata object is understandable and can also describe the relationship between the object.

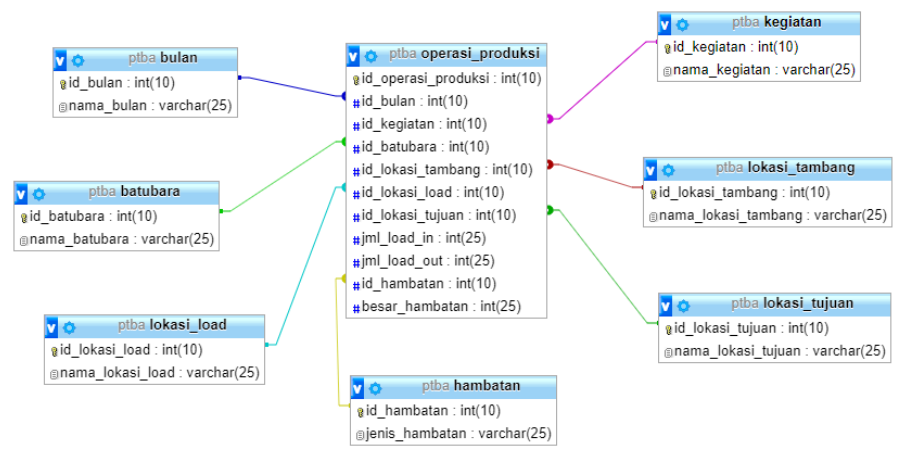

Fig. 3. Star Schema

Design Phase

After passing the business analysis stage, the next step is to carry out the design process, in which at this stage there are 3 main activities, namely:

Database Design

At this stage the BI database design process is carried out based on the needs analysis that has been carried out in the Business Analysis Phase of the Project Requirement Definition. So the BI database design that will be created is a multidimensional database.

Extract/Transform/Load (ETL)

ETL process is designing an ETL process flow for integrating data from a data source to a data warehouse. This process is the most complex in a BI project because this is where the quality of a data warehouse is taken into account, where the data validation process, data cleansing is done in the ETL process.

Meta data Repository Design

At this stage the design of the repository metadata analysis was conducted in the previous stage, namely Planning phase.

Construction Phase

This stage applies the design that has been made in the previous stages. At this stage there are 4 main activities, namely:

Extract/transform/load development

Running the ETL process using tools namely the Pentaho Spoon that can support various operational data sources. 


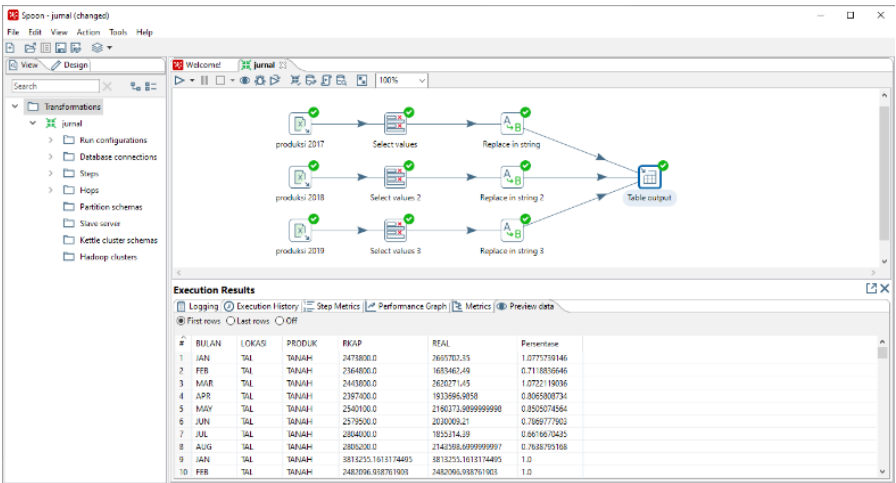

Fig. 4. The result of ETL Process

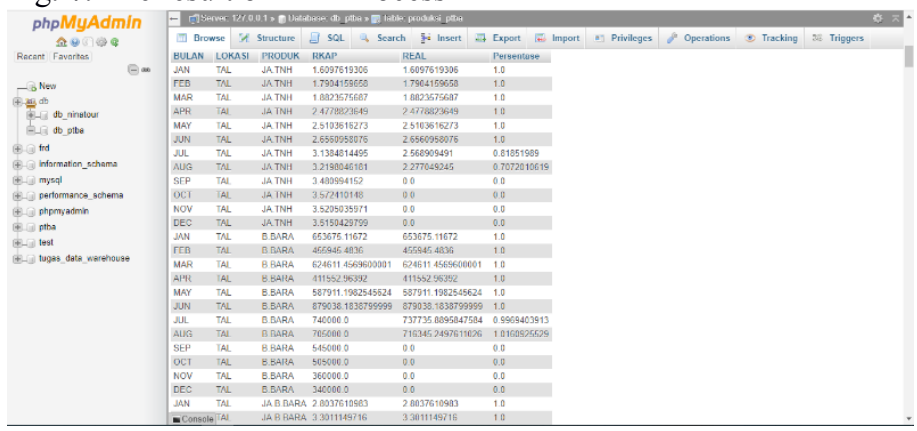

Fig. 5. Result of transformation in BI Database

If you have passed all the stages in ETL development, the next stage is making cube on multidimensional data for OLAP with the help of schema workbench tools. This tool can be published and saved with Pentaho dashboard analysis.

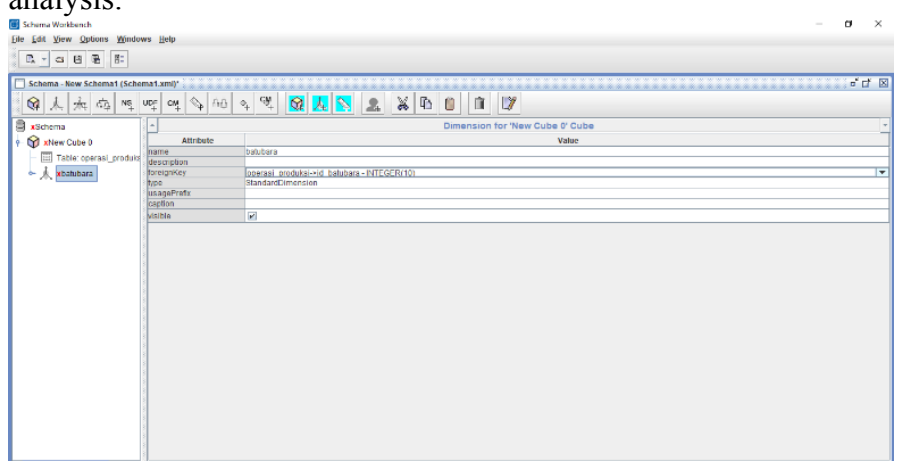

Fig. 6. Process of Schema Workbanch

Then, after the ETL and OLAP stages are carried out, the next stage is website development. Development of Business Intelligence tools for monitoring sales at PT. Bukit Asam, Tbk is divided into 2 main pages based on the role of users who interact with the system, namely PT. Bukit Asam, Tbk and admin, where each user has a menu according to their respective responsibilities.

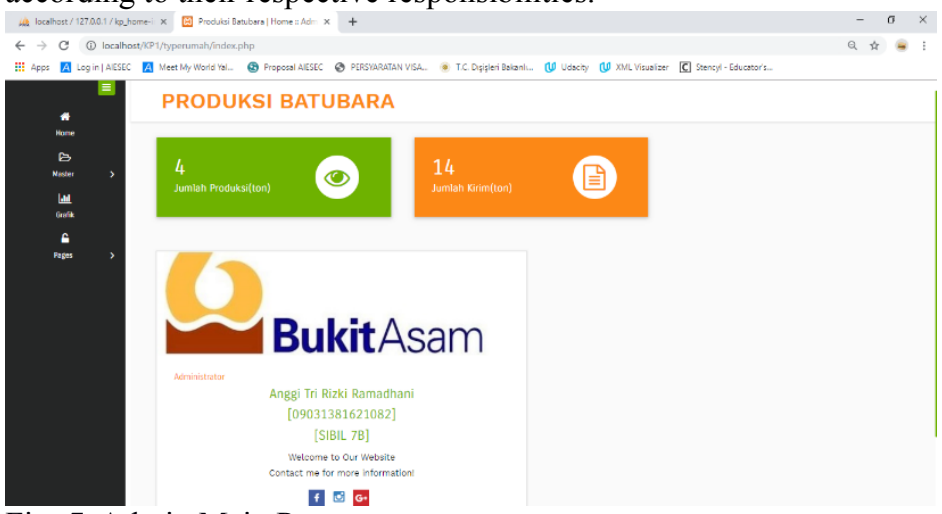

Fig. 7. Admin Main Page 


\section{REFERENCES}

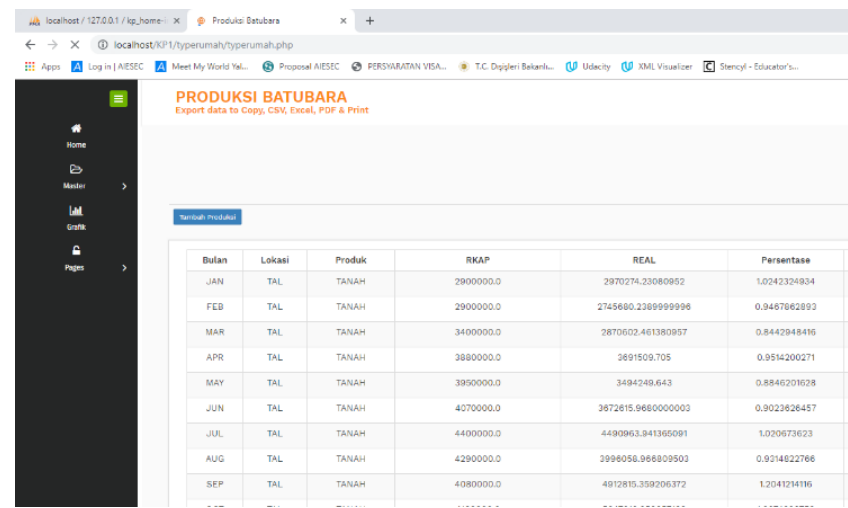

D. Prayitno, "Application of Business Intelligence for Banking Performance Based on Products Analysis," Int. J. Progress. Sci. Technol., vol. 6, no. 2, pp. 554-569, 2018.

Fig. 8. Interface Application of BI Development Following are the results of the data mining process that has been obtained using the classification method with the Naïve Bayes algorithm.

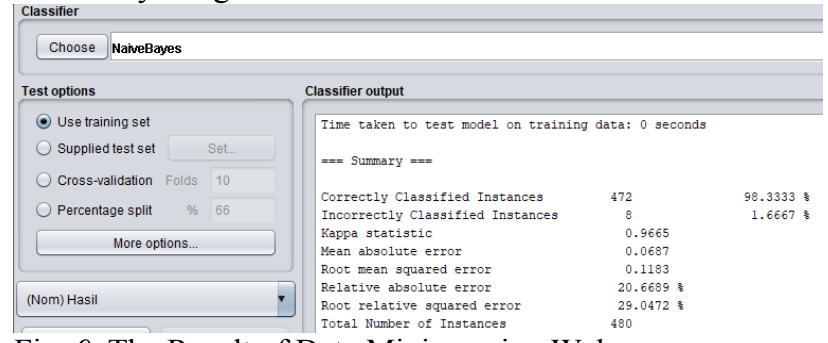

Fig. 9. The Result of Data Mining using Weka From the picture above test options is use training set, meaning some of data will be used as the data training. In addition it can be seen that the success rate is $98 \%$.

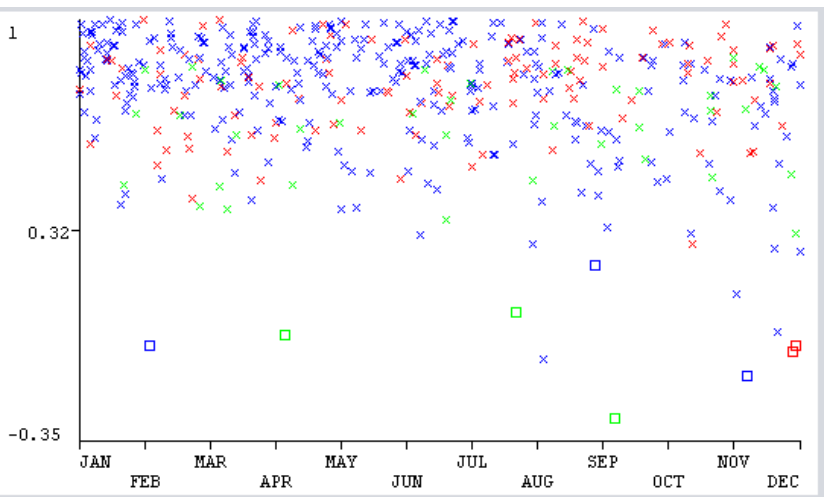

R. Shehzad and M. N. A. Khan, "Integrating knowledge management with business intelligence processes for enhanced organizational learning," Int. $J$. Softw. Eng. its Appl., vol. 7, no. 2, pp. 8392, 2013.

[3] M. Kubina, G. Koman, and I. Kubinova, "Possibility of Improving Efficiency within Business Intelligence Systems in Companies," Procedia Econ. Financ., vol. 26, no. 15, pp. 300-305, 2015.

[4] D. S. Medhekar, M. P. Bote, and S. D. Deshmukh, "Heart Disease Prediction System Using Naive Bayes," Int. J. Enhanc. Res. Sci. Technol. Eng., vol. 2, no. 3, pp. 1-5, Mar. 2013.

A. I., T. T., and T. S., "Business Intelligence During Times of Crisis: Adoption and Usage of ERP Systems by SMEs," Procedia - Soc. Behav. Sci., vol. 175, pp. 299-307, 2015.

[6] S. S. Wiradarma, K. D. Tania, and D. Y. Hardiyanti, "Implementation of Business Intelligence in Product Services a Banking (Case Study: PT Bank Sumsel Babel Baturaja Branch)," J. Sist. Inf., vol. 9, no. 2, pp. 1242-1247, 2017.

From the results of the above pattern can be taken into consideration for PT. Bukit Asam, Tbk. So as to increase the amount of coal production so that it is expected to be in accordance with the Work Plan and Budget (RKAP) that has been set at the beginning of the year.

\section{CONCLUSION}

By implementing Business Intelligence at PT. Bukit Asam, Tbk can provide facilities for the optimization process in coal production. In addition, the application of Business Intelligence makes it easy to make reports and reports are also easy to access and easy to understand (user interface). The leadership of PT, Bukit Asam, Tbk can also access the report easily because the data warehouse has been implemented and the query in it so that report format can be requested according to the leadership's needs. The results of this report can also help leaders in making business decisions in the future.

[7] J. Chongwatpol, "Managing big data in coal-fired power plants: a business intelligence framework," Ind. Manag. Data Syst., vol. 116, no. 8, pp. 1779-1799, Jan. 2016.

[8] G. A. Davis and C. R. Woratschek, "Evaluating Business Intelligence / Business Analytics Software for Use in the Information Systems Curriculum," Inf. Syst. Educ. J., vol. 13, no. 1, pp. 23-29, 2015.

[9] T. Zhanglu and H. Qian, "Research and design of intelligent coal-loading system with process reengineering," J. China Coal, no. 5, pp. 78-81, 2015. 